www.jmscr.igmpublication.org

Impact Factor 5.244

Index Copernicus Value: 83.27

ISSN (e)-2347-176x ISSN (p) 2455-0450

crossref DOI: http://dx.doi.org/10.18535/jmscr/v4i8.49

Journal Of Medical Science And Clinical Research

\title{
Patient's Knowledge on Commonly Occurring Diseases - A Survey
}

\author{
Authors \\ *Maria Kurian ${ }^{1}$, Prabu Shankar ${ }^{2}$ \\ ${ }^{1}$ 3rd year BDS, Saveetha Dental College \& Hospitals, Chennai \\ ${ }^{2}$ Surgeon, Saveetha Medical College \& Hospital, Chennai \\ *Corresponding Author \\ Maria Kurian \\ Email:mariaugust15@gmail.com
}

\begin{abstract}
Aim: The aim of this study is to assess the patient's knowledge on various commonly occurring diseases. Objective: The objective of this study is to create awareness among individuals about various diseases. Materials and method: Questionnaire will be prepared using the factors associated with various diseases such as Heart diseases, Hyperthyroidism, Hypothyroidism, Diabetes and Hypertension. Patients of various age groups visiting Saveetha Dental College and Hospital were selected for this study. Those who were not willing to participate in this study were excluded.

Background: Various changes from normal such as appearance of a small swelling or ulcer, frequent urination, dizziness goes unnoticed and later leads to several complications. Hence awareness for individuals is required for early detection.

Reason: Not many people are aware of the various symptoms of diseases, hence early detection and treatment of the disease is not possible. Awareness of these diseases can prove useful for the control and treatment of the disease.

Result: It was seen that the individuals were aware about the commonly occurring diseases but lacked adequate knowledge about these diseases.
\end{abstract}

\section{INTRODUCTION}

The common diseases indicated in the questionnaire includes heart diseases, hyperthyroidism, hypothyroidism, diabetes and hypertension. Cardiovascular diseases (CVDs) are group of disorders that involve the heart or blood vessels or both. They include coronary heart disease (CHD), cerebrovascular disease, peripheral arterial disease, rheumatic heart disease, congenital heart disease, and deep vein thrombosis and pulmonary embolism ${ }^{(1)}$. CVDs are the leading cause of deaths in both developed and developing countries. In 2008, 30\% (17.5 million people) of global all-cause mortalities were from CVDs. Of these, 6.2 and 7.3 million were due to stroke and CHD, respectively. It is expected to increase to 23.3 million by $2030^{(2)}$. Knowledge about CVD and its modifiable risk factors is a vital prerequisite to change the individuals' health attitudes, behaviors and lifestyle practices ${ }^{(3,4)}$. Thyroid disorders are very common in $\operatorname{India}^{(5)}$. Even then people do not have adequate knowledge about $\mathrm{it}^{(6)}$. India is considered as the diabetic capital of the world. There are approximately 3.5 
crore diabetics in India, and this figure is expected to increase up to 5.2 crore by 2025 . Keeping in view the alarming increase in the incidence and prevalence of diabetics in India, the World Health Organization (WHO) has declared India as the 'Diabetic Capital' of the world. ${ }^{(7)}$ Studies have shown that increasing patient knowledge regarding disease and its complications has significant benefits with regard to patient compliance to treatment and to decreasing complications associated with the disease. ${ }^{(8)}$

Hypertension is an extremely common medical problem, accounting for approximately ten percent of office visits to family physicians. ${ }^{(9,10,11)}$ All these diseases are seen often, thus awareness of these diseases among the people is required so as to prevent and manage these diseases.

\section{MATERIALS AND METHODS}

A questionnaire based study was conducted to assess the the patient's knowledge on various commonly occurring diseases. Patients visiting Saveetha Dental College and Hospital, Chennai were selected for this study. Data were collected using structured, self-administered questionnaire which was designed after reviewing the recent literature and similar questionnaires. The questionnaire included data such as age, gender and general questions related to commonly occurring diseases. The questionnaire was distributed to 20 random patients whose age was within 20-50 years. The questionnaires were distributed and explained to them after obtaining their verbal consent. Questionnaires were collected after being completed. All questionnaires were anonymous, and collected data were kept confidential and not used except for the study purpose.

\section{RESULTS}

The study results showed that only $93 \%$ of the individuals were aware about a gland called thyroid. $93 \%$ of them were also aware about hyperthyroidism and hypothyroidism. 13\% of the individuals felt that hypothyroidism leads to excessive weight gain whereas, $7 \%$ strongly felt that it does not and the remaining individuals did not know. $90 \%$ of the individuals felt that thyroid medications must be stopped during pregnancy. $7 \%$ suggested that medications must not be stopped and the remaining 3\% did not know. $7 \%$ of the individuals felt that cabbages, cauliflower and soya should be avoided during hypothyroidism. $10 \%$ of the individuals felt that it need not be avoided and the remaining $83 \%$ did not know. $93 \%$ of the individuals felt that thyroid medications must be stopped once the thyroid tests come as normal and the remaining $7 \%$ did not know. $90 \%$ of the individuals did not know if thyroid deficiency could be corrected with iodized salt and the remaining $10 \%$ suggested that it would not work. Of all the individuals participating in the study, $93 \%$ of them were educated about thyroid diseases. All the individuals were aware about heart attack. Only $60 \%$ of the individuals were able to accurately point out to the site of pain. $73 \%$ of the individuals answered that heart attack pain is a radiating type of pain. $63 \%$ of them suggested that high cholesterol diet causes heart attack whereas, $17 \%$ of them felt it was due to obesity, $10 \%$ felt it was because of high BP, $3 \%$ felt it was due to diabetes and the remaining 3\% felt it was caused due to smoking. When asked about the symptoms of a heart attack, $90 \%$ of them answered that it was pain over the chest region, $7 \%$ of them said that it is a radiating pain and $3 \%$ said that it was dizziness. When asked on how one can reduce the risk of heart attack, $80 \%$ suggested a balanced diet, $7 \%$ suggested exercise, $10 \%$ suggested reduced activities and 3\% suggested bed rest. 97\% answered that people with high blood pressure cannot carry out normal day to day activities, the remaining 3\% suggested that they can. When asked if fatigue is a common sign of high or low BP, $93 \%$ of them said yes and the remaining $7 \%$ said no. $90 \%$ of the individuals felt that high BP is due to large intake of salt. All of the individuals feel that blood pressure is related to heart problems. $17 \%$ of the individuals felt that 


\section{JMSCR Vol||04||Issue||08||Page 11979-11984||August}

headache is a common sign of high BP. All the individuals were aware about diabetes. When asked about the tests to be followed out to check diabetes, $77 \%$ suggested for a blood test and $23 \%$ suggested for kidney function test. $100 \%$ of the individuals were aware about both hyperglycemia and hypoglycemia. When asked for the signs of diabetes, 93\% suggested that it was weight gain and the remaining $7 \%$ said that it was poor wound healing. $20 \%$ of the individuals felt that diabetes is a curable disease and $50 \%$ of them strongly suggested that it cannot be cured, the remaining $30 \%$ did not know.

Table.1- Percentage results of the questionnaire.

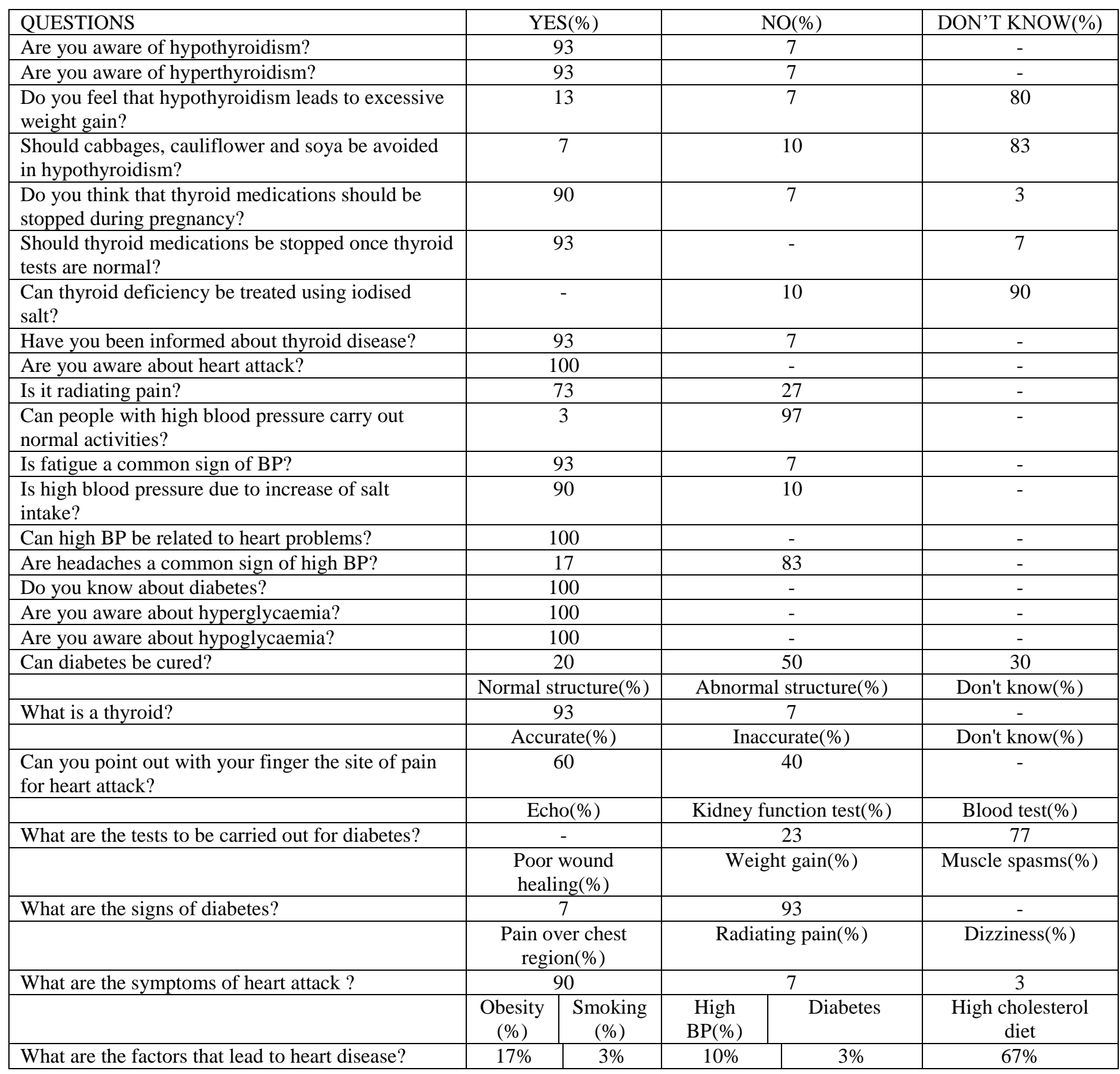


Figure.1- Awareness about diseases affecting the body.



\section{DISCUSSION}

In general, the patients with thyroid disorders had inadequate knowledge of thyroid gland and associated disorders. These findings are similar to those obtained by previous authors. ${ }^{(12,13)}$ Patients should be educated for the various symptoms of thyroid disorders. Patients commonly attribute that any symptom like sore throat in relation to neck is due to thyroid. Screening for thyroid disorders should be a part of routine health screen in people after the age of 35 years, pre and postmenopausal women, child-bearing women, and in pregnancy and postpartum period. ${ }^{(14-17)}$ There is a common misconception of excessive weight gain and obesity with hypothyroidism. In the present study, $80 \%$ patients thought that hypothyroidism

causes excessive weight gain, while it is well known that primary hypothyroidism does not cause an increase in weight of more that $2-3 \mathrm{~kg}$ although a symptom of "feeling heavy" is common among patients. ${ }^{(18)}$ Patients need to be educated that thyroid medication should not be stopped during pregnancy; apart from iodine deficiency there are immunological causes (Hashimoto's thyroiditis) resulting in hypothyroidism. Patients should also be educated for tests for treatment monitoring and long-term nature of treatment.

This study was also done to demonstrate the current level of public knowledge about of CVD, warning symptoms of heart attack or stroke and
CVD risk factors. $100 \%$ patients were aware of CVD. The present findings would be the first step in providing a quantitative measurement of CVD knowledge and identifying specific knowledge gaps. $100 \%$ patients could identify at least one of the symptoms of heart attack. Chest pain was the most common known symptom (90\%), which is close to that found in Beijing ${ }^{(19)}$ Radiating pain was recognized by $7 \%$ of the study population, which is lower than that reported in by studies from North Ireland and Nepal. ${ }^{(20)}$ 'Feeling weak, light-headed, or faint' was recognized by $3 \%$ of participants, which is close to that reported in North Ireland and Nepal ${ }^{(20)}$ Respondents' knowledge regarding the CVD risk factors was better than that for the warning symptoms of heart attack and stroke. The commonest risk factors identified by over four-fifths of the study participants were smoking, obesity, unhealthy diet and physical inactivity. High cholesterol diet was identified as the most common risk factor in this study, which is consistent to that reported in Pakistan. ${ }^{(21)}$

There have been several community studies about awareness of hypertension ${ }^{(22,23)}$ in the general population. Awareness of hypertension among those affected by the disease tends to be generally higher than in the general population in our environment. ${ }^{(24)}$ Prompt and adequate treatment of hypertension will delay onset of complications and might reverse some end organ damage. ${ }^{(25)}$ The majority believed that drugs should be taken only 
when they have "symptoms" or for a period of time.

Patients' knowledge regarding the treatment and complications of diabetes showed serious deficiencies, more so among women, even though most had been diabetic for years. The fact that $20 \%$ patients thought that diabetes is curable, and that only $50 \%$ patients correctly said that the treatment continues throughout the life, may reflect a mentality of patients that once the blood sugars are controlled, they can stop taking their medicines. The fact that although $77 \%$ of the patients were aware of how often they should have their blood sugars tested, only $20 \%$ were actually aware of their target fasting and postprandial blood sugars; this also indicates an overdependence on the physician and a lack of empowerment of the patient. This study confirms that patient knowledge about the treatment and complications of diabetes is limited, especially with regard to preventive aspects. There is a definite need to empower patients with the knowledge required to help them obtain maximum benefit from their treatment for diabetes.

\section{CONCLUSION}

The overall results from this study shows that awareness on the commonly occurring diseases such as thyroid disease, hypertension, hypotension, diabetes is comparatively low among the patients visiting Saveetha Dental College and Hospital. Awareness on Heart disease is slightly more when compared to the other diseases. Proper awareness must be given to people so as to reduce the incidence of such diseases.

\section{REFERENCES}

1. World Health Organization: Cardiovascular diseases. http://www.euro.who. int/en/health-topics/noncommunicabledise -ases/cardiovascular-diseases/ cardiovascular-diseases $2 /$ definition-of-cardiovascular-diseases.

2. World Health Organization: Cardiovascular diseases (CVDs): Fact sheet No. 317. http://www.who.int/mediacentre/factsheets /fs317/en/.

3. Becker MH, Maiman LA, Kirscht JP, Haefner DP, Drachman RH: The Health Belief Model and prediction of dietary compliance: a field experiment. J Health Soc Behav 1977, 18:348-366.

4. Ford ES, Jones DH: Cardiovascular health knowledge in the United States: findings from the National Health Interview Survey, 1985. Prev Med 1991, 20:725736.

5. Desai MP. Disorders of thyroid gland in India. Indian J Pediatr 1997;64:11-20.

6. Knowledge, Awareness, and Practices Among Patients with Thyroid Swelling Attending Cytology Clinic in a Medical College, Meerut A Singh, B Sachan, NP Malik, VK Sharma, N Verma, CP Singh Indian Journal of Clinical Practice, Vol. 24, No. 8, January 2014

7. Gupta V, Suri P. Diabetes in elderly patients. JK Practitioner. 2002;91:258-9.

8. Heisler M, Pietee JD, Spencer M, Kieffer E, Vijan S. The relationship between knowledge of recent $\mathrm{HbA1c}$ values and diabetes care understanding and selfmanagement. Diabetes Care. 2005;28:81622.[PubMed]

9. Tennev JB, White KL, Williamson JW: National Ambulatory Medical Care Survey: Backgrounid (itd Methodology. Vittl Health Stat [2] Series 2, 1974 April; 61:1-76.

10. Marsland DW, Wood M, Mayo F: A data bank for patient care, curriculum and research in family practice: 526, 196 patient problems. J Faim Pract 1976; 3:25.

11. Roseniblatt RA, Cherkin DC, Schneeweiss $\mathrm{R}$, et al: The structur-e and content offamily practice: Curremit status and future trends. J Fam Pract 1982; 15:631722.

12. Kannan S, Mukundan L, Mahadevan S, Sathya A, Kumaravel V, Bhat RV, et al. 
Knowledge, awareness and practices (KAP) among patients with hypothyroidism attending endocrine clinics of community hospitals in Chennai. Thyroid Res Practice 2010;7:11-5.

13. Mallik AK, Anad K, Pandav CS, Achar DP, Lobo J, Karmarkar MG, et al. Knowledge, beliefs and practices regarding iodine deficiency disorders among the tribals in Car Nicobar. Ind $\mathbf{J}$ Pediat 1998;65:115-20.

14. Ladenson PW, Singer PA, Ain KB, Baghi $\mathrm{N}$, Bigos ST, Levy EG, et al. American Thyroid Association guidelines for detection of thyroid dysfunction. Arch Intern Med 2000;160:1573-5.

15. Canadian Task Force on the Periodic Health Examination. Canadian Guide to Clinical Preventive Health Care. Ottawa: Canada Communication Group 1994;6118.

16. AACE Thyroid Task Force. American Association of Clinical Endocrinologists medical guidelines for clinical practice for the evaluation and treatment of hyperthyroidism and hypothyroidism. Endocr Prac2002;8:457-69.

17. American College of Obstetricians and Gynaecologists. Thyroid Disease in Pregnancy. Technical Bulletin no. 37. Washington, DC: American College of Obstetricians and Gynecologists 2002

18. ATA Patient Education Web Brochures. Thyroid and weight.

19. Zhang QT, Hu DY, Yang JG, Zhang SY, Zhang XQ, Liu SS: Public knowledge of heart attack symptoms in Beijing residents. Chin Med J (Engl) 2007, 120:1587-1591.

20. Al Hamarneh YN, Crealey GE, McElnay JC: Coronary heart disease: health knowledge and behaviour. Int $\mathbf{J}$ Clin Pharm 2011, 33:111-123.

21. Khan MS, Jafary FH, Jafar TH, Faruqui AM, Rasool SI, Hatcher J, Chaturvedi N:
Knowledge of modifiable risk factors of heart disease among patients with acute myocardial infarction in Karachi, Pakistan: a cross sectional study. BMC Cardiovasc Disord 2006, 6:18.

22. Marques-Vidal P, Toumilehto J. Hypertension awareness, treatment, and control in the community. Is "the rule of halves" still valid? J. Hum. Hypertens. 1997; 1 1:213-220.

23. Jaddan HY, Bateiha AM, Ajlouni KM. Prevalence, awareness and management of hypertension in a recently urbanized community in Eastern Jordan. JHum Hypertens. 2000;14:497-501.

24. Familoni OB. Hypertension-How much do our patients know? Afr Health. 2002;24: 13.

25. Liebeson RR, Serry RD. Significance of echocardiographic left ventricular mass, part II. Left-ventricular remodeling, risk, and therapeutic models for regression. Cardiol Inter 2001 ;2: 158-167. 